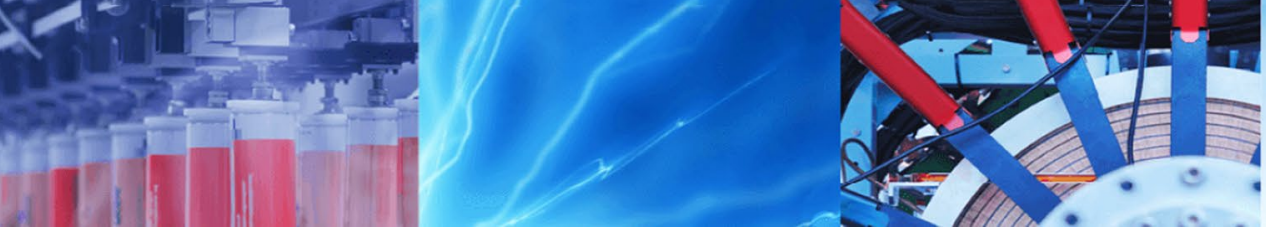

Research Article

\title{
Stator fault diagnosis of a BLDC motor based on discrete wavelet analysis using ADAMS simulation
}

\author{
Saba M. Hosseini ${ }^{1}$ (1) $\cdot$ Faezeh Hosseini ${ }^{1} \cdot$ Mostafa Abedi $^{2}$
}

(c) Springer Nature Switzerland AG 2019

\begin{abstract}
In this paper, a method is considered to observe the stator inter-turn fault (SITF) in brushless DC motors (BLDCM). This is a crucial subject to deal with, since the fault may cause expensive replacement of parts in case of late diagnosis. The approach used here is the discrete wavelet transform, which is one of the many kinds of time-frequency analysis approaches. Taking advantage of a model closely related to a real BLDCM, the stator current is simulated and the aforesaid signal-based method is applied to it. The feature used as a parameter to determine whether SITF has occurred or not is the average change or deviation in the energy amount of four signals named high frequency (detail) signals. In other words, first, the difference percentage of the energy parameters between those four signals in healthy and faulty operation mode would be measured. Then, the average percentage of the energy variation amounts are to be compared with a threshold to determine the fault occurrence. Having a precise Simulink/Matlab plus ADAMS model of the motor, the designed algorithm will be validated.
\end{abstract}

Keywords Fault detection $\cdot$ BLDC motor - Stator inter-turn fault · Discrete wavelet transform · Signal-based method

\section{Introduction}

BLDC motors have found increasing applications due to high dynamic response, better efficiency, and reliability. Applications such as the chemical industry, aerospace systems, and electric vehicles are much more important among others [1,2]. When this equipment operates in an unhealthy condition, it may have a paramount impact on product efficiency or system reliability and safety. Thereby, fast fault detection and localization is of profound importance to help to monitor the operation process of this equipment [2]. Different faults may happen in BLDC motors which may be due to electronic or electromechanical defects. They include bearing, stator, dynamic and static imbalances or damaged permanent magnet [1, $3,4]$. The mentioned faults and the corresponding fault detection (FD) and compensation methods have been thoroughly investigated in the literature. The researchers in [5] consider design, simulation and experimental implementation of a wavelet basis function network learning controller for linear BLDC motors. They are also concerned about the resulted robustness with position tracking and dealing with external disturbances. To control the nonlinear BLDCM system, an approach was introduced in [6] with a single neuron proportional-derivative-integral (PID) adaptive controller based on wavelet neural network online identification. A fault-tolerant torque controller for BLDC motors was introduced in [7]. It can keep precise production of torque while the power dissipation is still minimum, even if one of its phases break down.

There are plenty of fault detection methods which are mostly based on the control system modeling, so they only detect the faulty actuator and not the internal fault causes. Some of these works include the unknown input observer

Saba M. Hosseini, saba.mhosseini@gmail.com; Faezeh Hosseini, seyede.faezeh.hosseini@gmail.com; Mostafa Abedi, mo_abedi@sbu.ac.ir | ${ }^{1}$ Electrical Engineering Department, Shahid Beheshti University, Tehran, Iran. ${ }^{2}$ Faculty of Electrical Engineering, Shahid Beheshti University, Tehran, Iran. 
[8], sliding mode observers [9] or $H^{\infty}$ [10]. A major limitation of these methods is their sensitivity to the model accuracy and uncertainties that affect the fault detection efficiency, leading to high miss alarm rates. A few recently published articles have done the modeling at the actuator level. For example, a data-based solution using neural networks for plasma pulsed thrusters was presented [11]. However, these methods require a rich set of data, Also, the fault causes are difficult to be determined or it cannot be specified accurately.

Motivated by the mentioned issues, another category of works for module status monitoring was proposed that uses a measured crucial signal such as the motor current or its vibrations. They can be categorized into time, frequency or time-frequency strategies. The fault detection based on the time-frequency strategies is among the evolved methods in this field that solves the problem of time-based ones in which the assumed signal should have evident changes in time. Also, the solutions based on the frequency domain are only applicable for stationary or periodic non-stationary signals $[12,13]$. Since the BLDC motors may be under no load, variable load or torque ripples, the measurement signals are generally dynamic and has a transient part. So, the frequency spectrum is time variable and so the pure time or frequency approaches are not so applicable. Recently, the time-frequency analysis tools for fault monitoring of electrical machines is an interesting research topic which has received growing attention. As an example of the related literature, three wavelet-based methods were suggested in [14] to detect and generally classify mechanical and electrical faults in electric motors. The authors of [15] perused the detection of bearing fault using hall effect sensors and a two-stage wavelet transform. Following that, they have studied the same fault with two other methods of detection, continuous wavelet transform, and discrete wavelet transform in [16]. Paper [17] has to do with the detection of inter-turns short-circuit (ITSC) and Broken Rotor Bars (BRBs) faults utilizing DWT method. The BRBs have also been considered in [18] while the method used here as a detection tool is multilevel wavelet decomposition. Research done in [19] uses the Wigner-Ville family of time-frequency distributions as a means to diagnose the rotor faults. A new method consisting of the analytic wavelet transform has been used in [20] for detecting dynamic eccentricity in BLDC motors. A simple fault diagnosis technique is proposed in [21] to detect switch faults of three phases voltage source inverter (VSI) drive in a closed-loop control scheme.

It is known that a considerable percentage of electrical motors faults belong to the stator winding and it is believed that the related faults initialize as unknown turn to turn short circuits in a coil and then they progress to phase-to-phase or phase-to-ground short circuits, leading to destructive impacts. Following these faults, the system should be immediately shut down. Therefore, fast fault detection and determining its location or extent, especially in the initial progress phase, can avoid the mentioned catastrophic results. Considering the mentioned importance, the current work was proposed to design an onboard algorithm to detect the short circuit/open circuit faults and introduces a measure to show the progress level of them. Concerning this topic, some works have been done in the literature. The open-circuit fault detection has been considered in a study [22] in which the authors present a straightforward algorithm for fault diagnosis that uses the measured phase current information and the operating characteristics of motors. The SITF and open phase fault in the BLDC motor for an aircraft actuator was studied in [23] by combining discrete wavelet methods and neural networks. The authors in [24] dealt with the short-circuit faults on the stator winding of a VSI-fed brushless dc motor using the wavelet transform. The low and high-frequency signals obtained by the DWT of SITF fault patterns were analyzed in [25] and determined their severity.

The authors in [26] discuss the vibration analysis of a single-phase open-circuit fault condition. The vibration signals are extracted from DWT and Sinusoidal Pulse Width Modulation (SPWM) techniques were applied for the control of the speed of BLDC Motor. Nevertheless, the contributions of our research are (1) we have considered the stator short-circuit fault; (2) we proposed a novel modeling method using a mechanical software named ADAMS and applied our algorithm on that. In other words, we used ADAMS software as a validation method for the BLDC motor and linked it to the Matlab model and evaluated that model; meanwhile, (3) a novel feature was defined to characterize the fault occurrence. Hence, there is no claim on the fault detection tool (DWT) or the motor itself, rather we have claim on the fault occurrence location and type (SITF), a closer-tothe-reality BLDC motor model (Matlab-ADAMS model), and the feature used as a fault detection criteria (the average variation percentage of energy). These are the items that are not included in the paper [26]. In addition, the mentioned paper has used some assumptions and algorithms which are not the same as ours. In this paper, a fault detection algorithm based on the DWT was developed to detect the short circuit or open circuit events in the stator of a typical BLDC motor and suggest a novel criterion which its deviation indicates the fault severity. It is obtained by extracting the average deviation values of the energy of high-frequency components in both healthy and faulty modes. These components are obtained after applying the DWT tool on the measured current signal. This analytical tool has proved itself to be an accurate and weighty method utilized for 
signal processing applications. It is a time-frequency based strategy that can be applied for both transient and steady-state conditions of the current signal. The proposed algorithms are first evaluated using the measured current obtained by a simulated model developed for the BLDC motor. In the suggested model, different electrical and mechanical relations of the motor have been derived and they are integrated in such a way that the simulated model behavior to be close to the real one. Since there may be some model mismatches in the introduced model, a novel modeling methodology has been suggested utilizing the ADAMS software. For this purpose, all mechanical parts and the related imbalances are included in the ADAMS section which is related to the stator and driver modules in the MATLAB. So, by conducting different faulty scenarios using the developed model, the performance of the algorithms is evaluated in near practical conditions. Accordingly, there is this confidence that the results in this work can be obtained for real equipment. An accurate model has been also derived for stator short-circuit and open-circuit. Utilizing this fault model, the current overshoot or variations can be simulated for different short circuit severities.

The main contributions of this paper are (1) using the proposed method, not only the occurred faults are alarmed at the equipment level, but also the fault causes due to internal elements are isolated, so it achieves more features compared to the module-level strategies like [8-10] (2) Since it is not a model-based approach like [9], so an accurate model of the module is not required, also, its efficiency is not affected by the model uncertainties (3) Compared to the work proposed in [27], the performance of the developed algorithms is not dependent on the richness of the data collection (4) The proposed method can be applied for both transient and steady state duration of the measured current, also both time and frequency features of the occurred fault can be extracted (5) Compared to the related works like [14, 28], high-frequency components obtained by the DWT are utilized to develop a novel energy based condition monitoring criterion, so that its deviation amount indicates the occurred fault and the severity of the winding short circuit (6). An ADAMAS simulator for the BLDC motor was developed to obtain a more rigorous evaluation of the developed algorithms.

The paper structure is as follows. In Sect. 2, the BLDC model is represented. In the remainder of this section, the SITF model and the fault frequencies are introduced and next, the ADAMS model is detailed. Section 3 includes the developed fault detection algorithm based on DWT. In Sect. 4, the performance of the proposed algorithms is evaluated by conducting different fault scenarios. Finally, the paper is concluded in Sect. 5 .

\section{Modeling}

In this section, first, the theoretical model of the BLDC motor is proposed; then the fault model and the related fault frequencies are obtained. Finally, the ADAMS simulator for the BLDC motor is developed.

\subsection{BLDC motor model}

The electrical motor, that is to say, brushless DC motor is responsible to attain the appropriate torque and angular momentum. It is worth mentioning that the mathematical model of the BLDC motor is very much like that of the conventional DC motor and one significant difference is that the phases which are involved in the motor drive performance, would have an influence on the resistive and the inductive character of this module structure [29]. An almost accurate model is required in order to obtain an accurate simulated of the measured current. The model used for BLDC motor in the paper is one of the most commonly used ones among researches such as $[30,31]$. The relations related to phase-to-phase voltages are as follows [32, 33]:

$V_{a b}=R\left(i_{a}-i_{b}\right)+L \frac{d}{d t}\left(i_{a}-i_{b}\right)+E_{a}-E_{b}$

$V_{b c}=R\left(i_{b}-i_{c}\right)+L \frac{d}{d t}\left(i_{b}-i_{c}\right)+E_{b}-E_{c}$

$V_{a c}=R\left(i_{a}-i_{c}\right)+L \frac{d}{d t}\left(i_{a}-i_{c}\right)+E_{a}-E_{c}$

where $L=I-M ; R, I, M$ are the resistance, self, and mutual stator winding inductances respectively; the stator currents of phases $a, b$, and $c$ are $i_{a}, i_{b}$ and $i_{c}$ respectively and phase to phase voltages and recursive electromotive forces of each phase are $V_{a b}, V_{b c}, V_{a c}, E_{a}, E_{b}$ and $E_{c}$ respectively. Besides, the followings are the mechanical equations for BLDC motor:

$T_{e}-T_{L}=J \frac{d^{2} \theta_{m}}{d t^{2}}+B \frac{d \theta_{m}}{d t}$

$\theta_{e}=\frac{P}{2} \theta_{m}$

$\omega_{m}=\frac{d \theta_{m}}{d t}$

wherein $T_{e}$ and $T_{L}$ are the electrical and the load torques respectively and $J$ is the moment of inertia of the rotor; $B$ 
is the damping coefficient due to friction; $\omega_{m}$ and $\theta_{m}$ are the velocity and the position of the rotor respectively. Also,

$T_{L}=T_{D B}+T_{D F}$

$T_{D B}=T_{\text {viscouse }}+T_{\text {coulomb }}=C_{v} \omega_{m}+C_{c} \operatorname{sign}\left(\omega_{m}\right)$

where $T_{D B}$ and $T_{D F}$ are bearing disturbance torque and flywheel disturbance torque respectively; $T_{\text {viscouse }}$ and $C_{v}$ are viscous friction and its coefficient respectively while $T_{\text {coulomb }}$ and $C_{c}$ are coulomb friction and its coefficient respectively. Furthermore, the electromagnetic torque of a BLDC motor which has $P$ poles would be as follows [32, 33]:

$T_{e}=K_{T}\left(F\left(\theta_{e}\right) i_{a}+F\left(\theta_{e}-\frac{2 \pi}{3}\right) i_{b}+F\left(\theta_{e}+\frac{2 \pi}{3}\right) i_{c}\right)$

$K_{T}=2 P N_{s} B_{f} l r$

here $F\left(\theta_{e}\right)$ specifies a trapezoidal function that is used to make the trapezoidal shape of the electromagnetic torque and the flux density. $K_{T}, N_{s}, B_{f}$ are respectively the torque constant, the number of winding turns in each stator phase and the mean flux in the air gap in Tesla; also / and $r$ are the rotor's length and radius respectively. The back electromotive force on each phase of stator windings are acquired as followings [31]:

$E_{a}=K_{e} \omega_{m} F\left(\theta_{e}\right)$

$E_{b}=K_{e} \omega_{m} F\left(\theta_{e}-\frac{2 \pi}{3}\right)$

$E_{c}=K_{e} \omega_{m} F\left(\theta_{e}+\frac{2 \pi}{3}\right)$

where $K_{e}$ is the induction electromotive constant. Finally, the above equations can be set in a specific order as below:

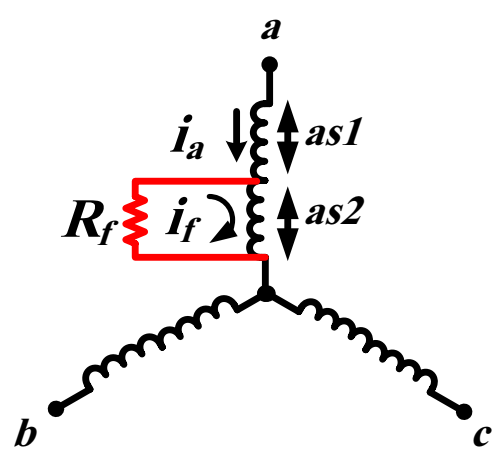

Fig. 1 Short inter-turn fault modeled in a 3-phase stator [12]

wherein the fault has occurred in the winding of phase a. In this Figure, the "as1" marks the healthy part of the winding, whereas "as2" marks the shorted winding section; $i_{a}$ shows the stator current while $i_{f}$ models the induced circulating current in the short-circuit section [34].

Figure 2 shows how the 3-phase stator can be modeled in both healthy (part a) and faulty (part b) operation modes. In this schema, $L_{c}, L_{b}, L_{a}, R_{c}, R_{b}, R_{a}$ are inductances and resistances of related stator phases respectively; besides, all " $R$ "s and " $L$ "s are considered equal to each other; $E_{c^{\prime}} E_{b}, E_{a}$ imply back emf whereas " $e_{f}$ " marks the back emf derived from short-circuit current; " $\mu$ " indicates the ratio of short-circuit turns to the whole number of turns in one phase.

The fault is applied to the stator current equations in (14). To apply fault impact in this equation, the inductance $L_{a}$ should be replaced by $\left(1-\mu^{2}\right) L_{a}$ and $(1-\mu) R_{a}$ is inserted instead of the resistance $R_{a}$. While the motor is working normally, the parameter $\mu$ is considered zero as illustrated in Fig. $2 \mathrm{a}$ and a non-zero $\mu$ leads to a faulty situation as shown in Fig. 2 b.

$\left(\begin{array}{c}\frac{d i_{a}}{d t} \\ \frac{d i_{b}}{d t} \\ \frac{d \omega}{d t} \\ \frac{d \theta_{m}}{d t}\end{array}\right)=\left(\begin{array}{cccc}-R / L & 0 & 0 & 0 \\ 0 & -R / L & 0 & 0 \\ 0 & 0 & B / J & 0 \\ 0 & 0 & 1 & 0\end{array}\right)\left(\begin{array}{c}i_{a} \\ i_{b} \\ \omega_{m} \\ \theta_{m}\end{array}\right)+\left(\begin{array}{lll}2 /(3 L) & 1 /(3 L) & 0 \\ -1 /(3 L) & 1 /(3 L) & 0 \\ 0 & 0 & 1 / J \\ 0 & 0 & 0\end{array}\right)\left(\begin{array}{c}V_{a b}-E_{a b} \\ V_{b c}-E_{b c} \\ T_{e}-T_{L}\end{array}\right)$

in which $E_{a b}=E_{a}-E_{b}$ and $E_{b c}=E_{b}-E_{c}$ are determined as a phase to phase back Electromotive Forces (EMF) of the electrical motor. Also, the current $i_{c}$ would be obtained as:

$i_{c}=-\left(i_{a}+i_{b}\right)$

\subsection{The fault model and fault frequencies}

The stator inter-turn fault is very common in the BLDC motors. Hence, there is a need to represent a model for it to be able to evaluate the performance of the developed algorithms. Figure 1 shows a schematic of stator windings
In the stator current, there would be some harmonics built due to the SITF, having a pattern as below:

$f_{\text {SITF }}=(2 k-1) f_{f}$

where $f_{f}$ shows the fundamental frequency.

\subsection{The BLDC motor simulator using ADAMS software}

Although, the developed relations in the previous section describe different mechanical and electrical parts 


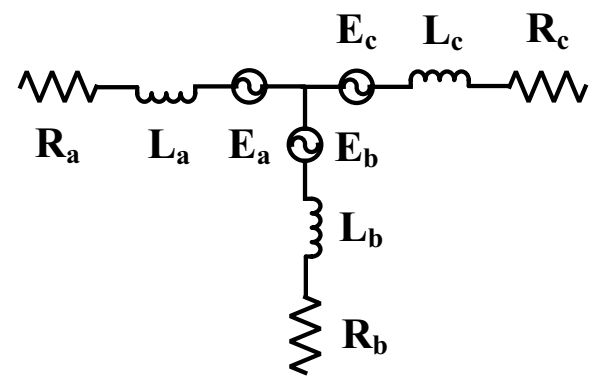

(a)



(b)

Fig. 2 a The healthy 3-phase stator. b The faulty 3-phase stator of the BLDC motor, however, there may be some model mismatches. Accordingly, a simulator using the ADAMS software has been developed in this section to accurately model the mechanical part of the BLDC motor including the related imbalance torques and relates it to the controller driver and the stator in MATLAB. Therefore, a more accurate simulation of the output current considering the actual operation condition of the BLDC motor can be captured.

ADAMS software is a proper tool to model the rotor. The strength of this model is that the static and dynamic imbalances are also modeled in the rotor model by mass-spring mechanisms. Figure 3 shows the schema of our work with both MATLAB and ADAMS. This Figure includes the illustration of the Eqs. (7) to (14) together with the ADAMS model. As illustrated in this Figure, the $\mathrm{PI}$ controller and the driver part produce $V_{a b}$ and $V_{b c}$ commands. Then, based on the Eqs. (14) and (15), the stator phase currents are built in the Stator Block1. The electromotive forces $E_{a}, E_{b}$ and $E_{c}$ obtained from the Stator Block3 and Eqs. (11) to (13) enter the Stator Block1. At that point, the electromagnetic torque $T_{e}$ would be produced through the Eqs. (9) and (10) in the Stator Block2 and the torque $T_{e}-T_{L}$ enters the rotor in the ADAMS block as the input. The rotor ADAMS block outputs the angular velocity, the mechanical angle, and the motor imbalances. Afterward, these parameters are sent to the

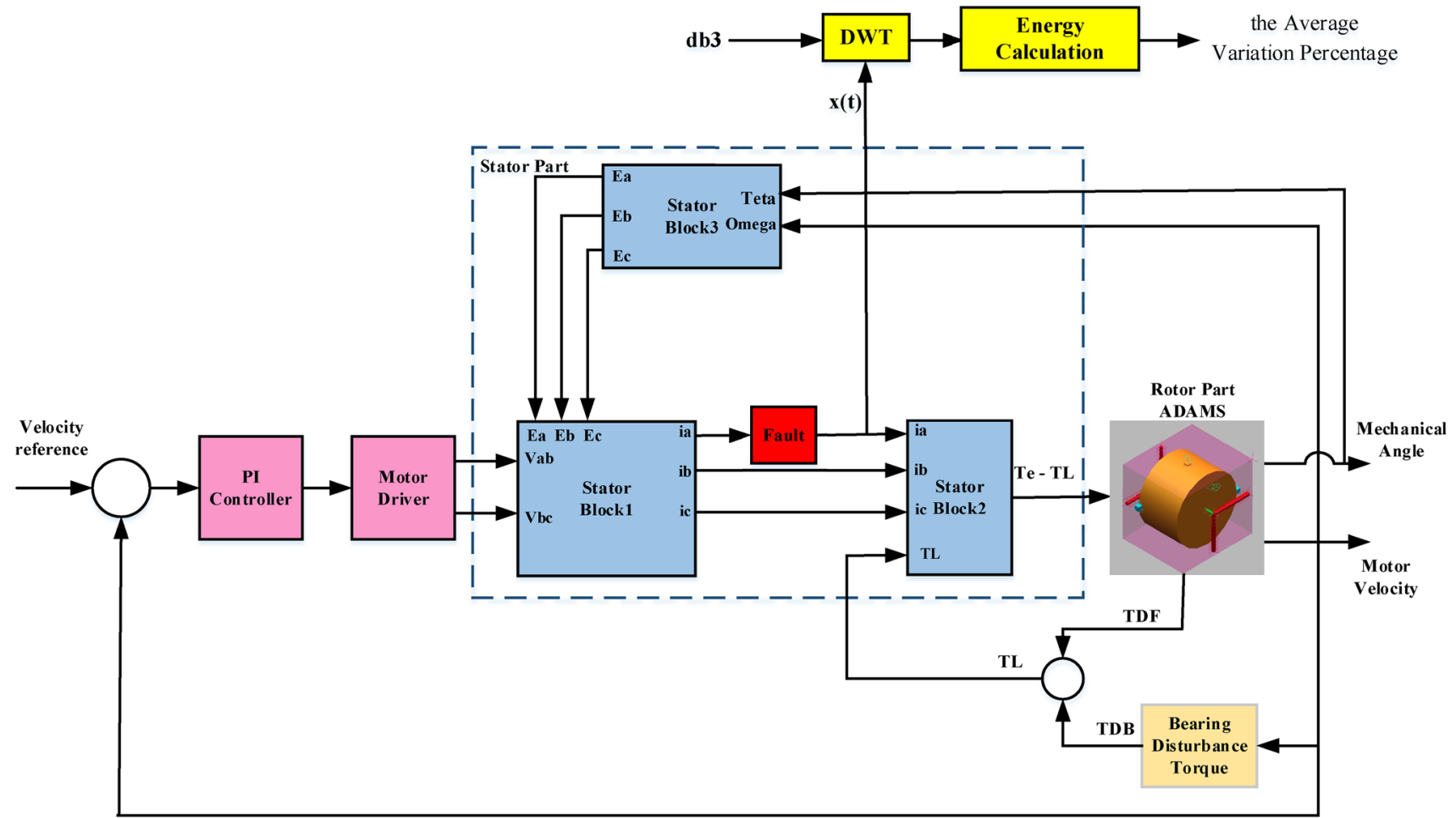

Fig. 3 The interface between the Matlab and ADAMS software 




$\downarrow 2$ Downsampling

Fig. 4 The process of Mallat decomposition algorithm

Matlab software for further calculations. This combination will help to validate the proposed fault detection algorithm in this paper.

\section{Discrete wavelet transform}

Discrete wavelet transform (DWT) is a more efficient analytical tool than Continuous Wavelet Transform in terms of solving the problem of data redundancy and it tries to remove redundant data. Giving sufficient and proper data for signal analysis, DWT greatly reduces the time and requirements of calculations. Furthermore, it benefits from low and high pass filters to decompose the time-domain signal into many scales for different frequency bands that cause a change in the sampling rate in each step [35]. Since DWT is formed on a binary strategy which refers to choosing the scale and position based on powers of 2, the output of this transformation is obtained by replacing $a=2^{j}$ and $b=k \cdot 2^{j}$ in the following equation [36]:

$W C(a, b)=\frac{1}{\sqrt{|a|}} \int_{-\infty}^{\infty} x(t) \overline{\psi\left(\frac{t-b}{a}\right)} d t$

Figure 4 illustrates the process of the Mallat decomposition algorithm. The coefficients related to high-frequency components of the signal are called $d_{i}$, while those related to low-frequency components are called $a_{i}$. In each step, the scales are altered by downsampling which is a reduction of the signal maintaining only one from two samples of each output signal.

It is necessary to determine the number of levels of decomposition for DWT to extract the features of fault. The number of levels is depended on the sampling period according to the equation below [37]:

$n=$ integer $\left(\frac{\log (F s / f n)}{\log (2)}\right)$
Table 1 The parameters of the MATLAB model

\begin{tabular}{lll}
\hline Symbol & Value & Parameter \\
\hline $\mathrm{R}$ & $8 \Omega$ & Phase resistor \\
$\mathrm{L}$ & $2 \times 10^{-3} \mathrm{H}$ & Phase inductance \\
$\mathrm{r}_{\mathrm{s}}$ & $9 \times 10^{-3} \Omega$ & Short-circuit impedance \\
$\mathrm{J}$ & $0.66 \times 10^{-3} \mathrm{~kg} \mathrm{~m}^{2}$ & Moment of inertia \\
$\mathrm{B}$ & $2 \times 10^{-5} \mathrm{~N} \mathrm{~m} \mathrm{~s} / \mathrm{rad}$ & damping coefficient \\
$\mathrm{k}_{\mathrm{e}}$ & $2 \mathrm{~N} \mathrm{~m} / \mathrm{A}$ & Induction electromotive coefficient \\
$\mathrm{K}_{\mathrm{T}}$ & $13.689 \times 10^{-3} \mathrm{~N} \mathrm{~m} / \mathrm{A}$ & BLDC motor torque coefficient \\
$\mathrm{C}_{\mathrm{c}}$ & $10^{-4} \mathrm{~N} \mathrm{~m}$ & Coulomb friction coefficient \\
$\mathrm{C}_{\mathrm{v}}$ & $2 \times 10^{-5} \mathrm{~N} \mathrm{~m} \mathrm{~s} / \mathrm{rad}$ & Viscous friction coefficient \\
$\mathrm{T}_{\mathrm{s}}$ & $5 \times 10^{-6} \mathrm{~s}$ & Sampling time \\
\hline
\end{tabular}

Table 2 the parameters related to the ADAMS simulator

\begin{tabular}{lll}
\hline Symbol & Value & Parameter \\
\hline $\mathrm{k}$ & $2.1 \times 10^{7}$ & Spring stiffness \\
$\mathrm{c}$ & 5067 & Spring damper \\
$\mathrm{h}$ & $2 \times 10^{-2} \mathrm{~m}$ & Cylindrical thickness \\
$\mathrm{R}$ & $8 \times 10^{-2} \mathrm{~m}$ & Cylindrical radius \\
$\mathrm{M}_{\mathrm{d}}$ & $3.125 \times 10^{-5} \mathrm{~g}$ & Dynamic imbalance mass \\
$\mathrm{M}_{\mathrm{s}}$ & $3.75 \times 10^{-6} \mathrm{~g}$ & Static imbalance mass \\
\hline
\end{tabular}

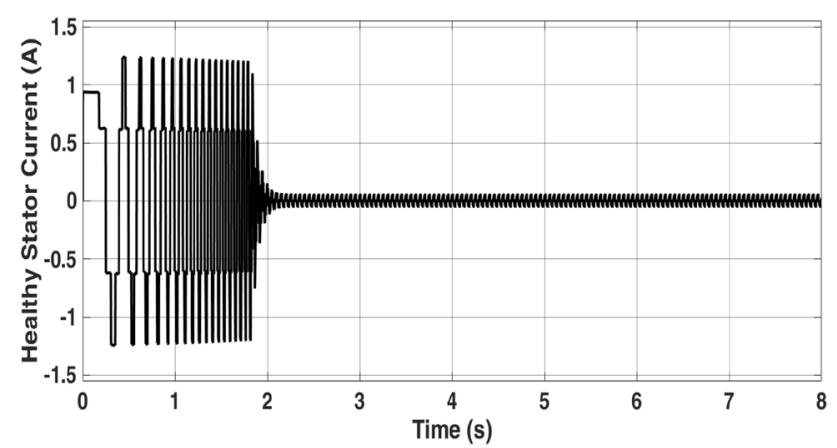

Fig. 5 Stator current waveform in healthy operation mode

where $F_{s}$ is the sampling frequency and $f_{n}$ is the frequency which includes the frequency span of component $d_{n}$. Each high-frequency signal $d_{i} i$ includes some information corresponded to the signal components. Indicating the sampling time period by $T_{s}$, the frequency span, which this high-frequency signal covers, is obtained as below [37]:

freq $\left(d_{j}\right) \in\left[\frac{1}{T_{s} 2^{j+1}}, \frac{1}{T_{s} 2^{j}}\right] \mathrm{Hz}$

whereas the approximation signal $a_{n}$ includes low frequencies and this frequency span is determined as follows [37]:

freq $\left(a_{n}\right) \in\left[0, \frac{1}{T_{s} 2^{j+1}}\right] \mathrm{Hz}$ 


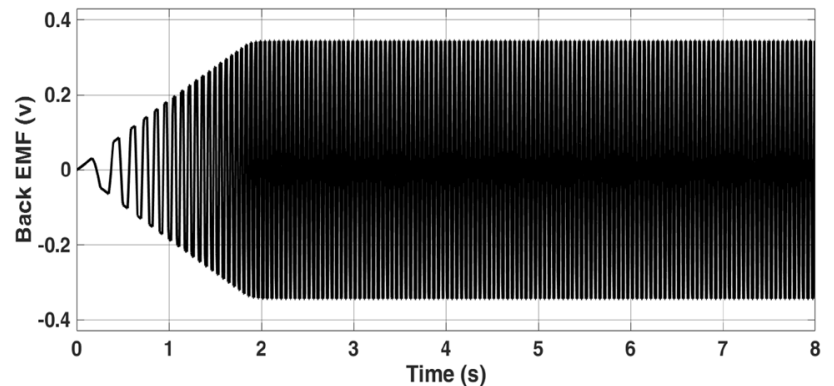

Fig. 6 Back-EMF waveform in healthy operation mode

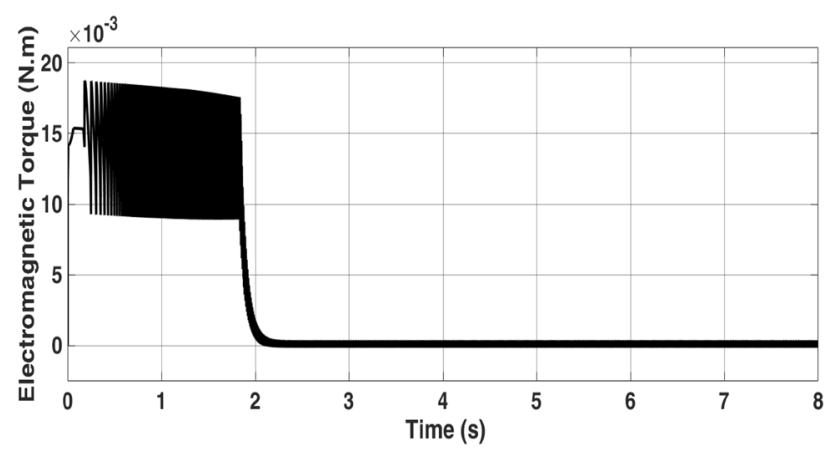

Fig. 7 Electromagnetic torque waveform in healthy operation mode

\section{The simulation results}

To confirm the validity of the proposed algorithms, the simulation results are proposed in this section. As was mentioned, the considered BLDC motor has been simulated by putting together two software, the Matlab and the ADAMS. The related parameters about these tools are illustrated in Tables 1 and 2.

Figures 5, 6 and 7 show respectively the stator current, back EMF and the electromagnetic torque in healthy operation mode. It is clear in all three Figures that the transient states take about $2 \mathrm{~s}$ before the parameters enter the stable phase.

Graphs of the stator current, back EMF and the electromagnetic torque in healthy operation mode are shown in Figs. 5, 6 and 7 respectively.

It is worth mentioning that the rotor speed is very small in the beginning but it grows to become stable at the desired speed $\omega_{m}=41.86 \mathrm{rad} / \mathrm{s}$. Based on the Eq. (16), considering the nominal speed of the rotor as $400 \mathrm{rpm}$ and also the number of poles as $6(P=6)$, the fundamental frequency would be equal to $20 \mathrm{~Hz}$ and the main and side frequencies related to failures would be $20,60,100$ and $140 \mathrm{~Hz}$. Next, it is aimed to diagnose the SITF from
Table 3 The frequency span of 13 high-frequency signals

\begin{tabular}{lll}
\hline & $\begin{array}{l}\text { Lower frequency boundary } \\
(\mathrm{Hz})\end{array}$ & $\begin{array}{l}\text { Upper-fre- } \\
\text { quency bound- } \\
\text { ary }(\mathrm{Hz})\end{array}$ \\
\hline D1 & 50,000 & 100,000 \\
D2 & 25,000 & 50,000 \\
D3 & 12,500 & 25,000 \\
D4 & 6250 & 12,500 \\
D5 & 3125 & 6250 \\
D6 & 1562.5 & 3125 \\
D7 & 781.25 & 1562.5 \\
D8 & 390.62 & 781.25 \\
D9 & 195.31 & 390.62 \\
D10 & 97.65 & 195.31 \\
D11 & 48.82 & 97.65 \\
D12 & 24.41 & 48.82 \\
D13 & 12.20 & 24.41 \\
\hline
\end{tabular}

the stator current after $8 \mathrm{~s}$ of motor initialization in which the transient condition of the stator current has been passed. The selected sampling time is $5 \times 10^{-6} \mathrm{~s}$, also the minimum frequency span to consider is $0-20 \mathrm{~Hz}$ and $f_{n}=20 \mathrm{~Hz}$. So, the minimum number of levels of discrete wavelet decomposition would be 13 according to (18). The frequency span for each of 13 high-frequency signals derived from (19) and (20) are mentioned in Table 3.

As for the fault frequencies, it is better to consider just $D_{10}$ to $D_{13}$ for SITF detection. The energy of these signals $E_{i}$ in both healthy and faulty mode would be then calculated by:

$E_{i}=\frac{1}{N} \sum_{k=1}^{N} \operatorname{Di}(k)^{2} ; \quad i=10,11,12,13$

wherein $N$ implies the number of samples in eachi $D_{i}$. The feature used as the fault detection criteria is the average percentage of the variation of each of $E_{i} s$ compared to the $\mathrm{E}_{i}$ of the healthy mode. Hence, the healthy operation mode energies of $D_{i} s, \mathrm{i}=10,11,12,13$ are also required. Accordingly, the difference percentage of the energy parameters between those four signals in healthy and faulty operation mode would be measured. Then, the average percentage of the energy variation amounts are to be compared with a threshold to determine the fault occurrence. In other words, by comparing the derived criterion with respect to some determined thresholds, the occurred faults will be decided and the related alarms will be declared.

In the following, the proposed algorithms are evaluated through five scenarios based on which both abrupt and time-variable SITF are covered. The first case is the 




Fig. 8 Stator current waveform in faulty operation mode case 1

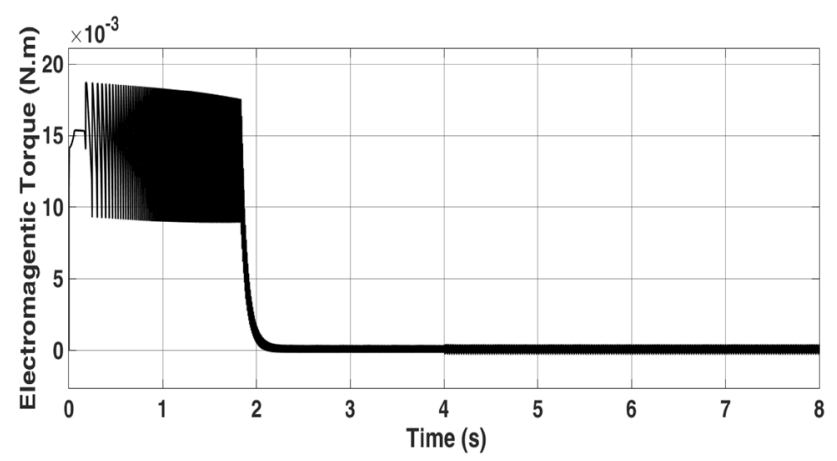

Fig. 9 Electromagnetic torque waveform in faulty operation mode case 1

occurrence of a constant abrupt fault from the motor startup to the end of the transient phase. The second one is again a constant sudden fault which happens after the stator current reaches its static state; also, the severity of the fault, which refers to the value of the parameter $\mu$, is doubled. In the third scenario, a time variable fault is considered that starts at time $t=4$ after motor startup with the initial value of 0 and the slope of 0.125 ; that means the parameter $\mu$ is initially 0 at this time, but it increases to be 0.5 at time $t=8$. The fourth scenario describes the faulty situation with the existence of load torque and characteristics of fault case 1 . Finally, case 5 is about faults happening in two phases of stator instead of one, that is, fault case 2 occurs in the phase "a" while

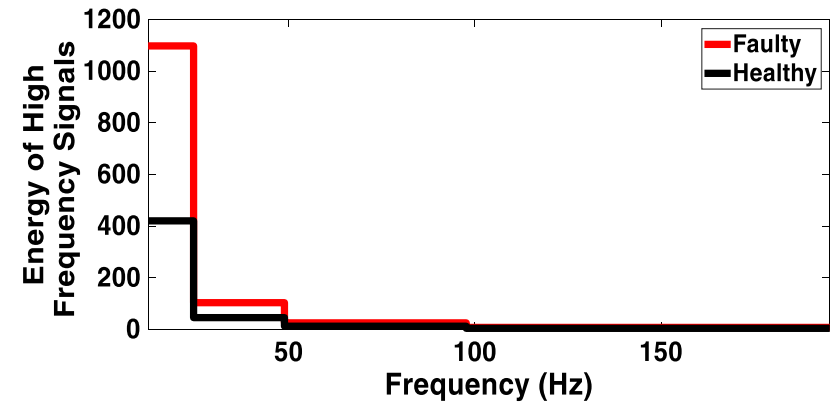

Fig. 10 The frequency-energy diagram for fault case 1

fault case 1 happens in the phase "b" of stator. So, the cases are as follows:

- Case 1: SITF starts at time $t=4$ and $\mu=0.25$.

- Case 2: SITF starts at time $t=0$ and $\mu=0.5$.

- Case 3: SITF starts at time $t=4$ and $\mu$ has the initial value of 0 and increases with the slope of 0.125.

- Case 4: Fault case 1 and the existence of load torque simultaneously.

- Case 5: Fault case 2 happening in the phase "a", and fault case 1 happening in the phase " $b$ " of the stator.

The threshold of the average variation percentage of energy is considered $40 \%$ for the proper fault detection in all cases.

\subsection{Case 1}

By applying the fault described in case 1 to our MATLABADAMS simulation model and further calculations of energies according to (21), the faulty stator current and the electromagnetic torque signals shown in Figs. 8 and 9 are derived. Also, the related results have been illustrated in Table 4 and the respective frequency-energy diagram is shown in Fig. 10. Table 4 indicates that the energy increases when the fault happens and that is true for all 4 frequencies and the related high-frequency signals. Using the proposed detection algorithm leads to the successful detection of the fault. As it is clear from Fig. 8, fault has influenced the amplitude of the stator current to increase starting from time $t=4$.
Table 4 The energies of the healthy and faulty mode of case 1 and the calculated average variations

\begin{tabular}{lcccr}
\hline Energy operation mode & $\mathrm{E}_{10}$ & $\mathrm{E}_{11}$ & $\mathrm{E}_{12}$ & \multicolumn{1}{c}{$\mathrm{E}_{13}$} \\
\hline Healthy & 3.8568 & 12.0852 & 45.2893 & 420.0062 \\
Fault case 1 & 7.4129 & 25.0411 & 103.1622 & 1097.3415 \\
Variation percentage & $92.20 \%$ & $107.20 \%$ & $127.78 \%$ & $161.27 \%$ \\
Average variation percentage & $122.11 \%$ & & & \\
\hline
\end{tabular}




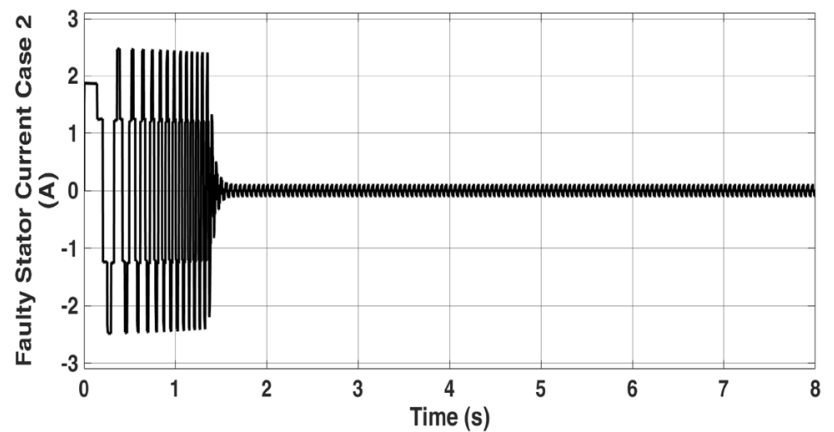

Fig. 11 Stator current waveform in faulty operation mode case 2



Fig. 12 Electromagnetic torque waveform in faulty operation mode case 2

The graph in Fig. 10 shows that the energy in all the related frequency spans of the high-frequency signals has increased to more than the threshold amount. The average variation percentage of faulty and healthy mode energy here is $122.11 \%$ which is more than $40 \%$, hence the fault occurrence is detectable in this case.

\subsection{Case 2}

Applying this fault case to the simulation model gives the faulty stator current and the electromagnetic torque signals shown in Figs. 11 and 12 respectively. The obtained results have been summarized in Table 5. Also, the concerned frequency-energy diagram is illustrated in Fig. 13. Figure 11 depicts that fault has influenced the amplitude of the stator current to increase starting from time $t=0$.

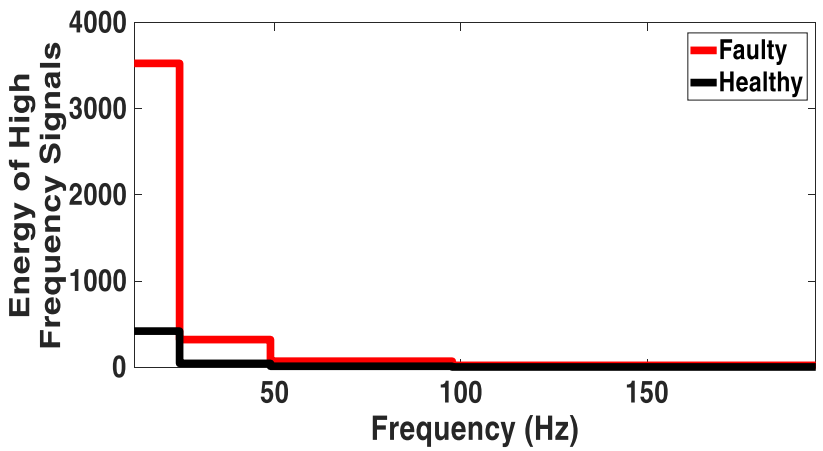

Fig. 13 The frequency-energy diagram for fault case 2

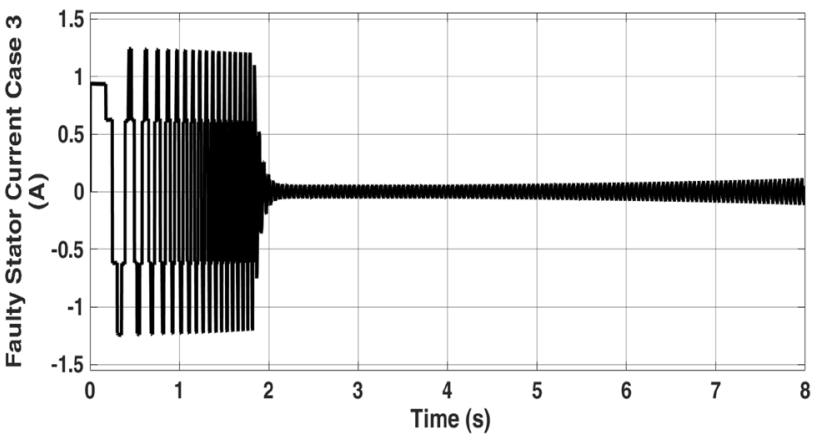

Fig. 14 Stator current waveform in faulty operation mode case 3

The average variation percentage of faulty and healthy mode energy here is $578.64 \%$ which is greatly more than $40 \%$ and passes the threshold amount by far. Hence, the fault occurrence is detectable in this case as well. It is clear that a greater amount of this criterion has been achieved for more severe defects.

\subsection{Case 3}

The faulty stator current, shown in Fig. 14, depicts a small increase slope after time $t=4$. The faulty electromagnetic torque which has increasing ripples is illustrated in Fig. 15.

To have a better view of fault detection, Fig. 16 illustrates the average variation percentage of energy obtained every second compared with the threshold amount which
Table 5 The energies of the healthy and faulty mode of case 2 and the calculated average variations

\begin{tabular}{lrrrr}
\hline Energy operation mode & \multicolumn{1}{c}{$\mathrm{E}_{10}$} & $\mathrm{E}_{11}$ & \multicolumn{1}{c}{$\mathrm{E}_{12}$} & \multicolumn{1}{c}{$\mathrm{E}_{13}$} \\
\hline Healthy & 3.8568 & 12.0852 & 45.2893 & 420.0062 \\
Fault case 2 & 22.2848 & 70.8671 & 321.7610 & 3527.1799 \\
Variation percentage & $477.80 \%$ & $486.39 \%$ & $610.60 \%$ & $739.78 \%$ \\
Average variation percentage & $578.64 \%$ & & & \\
\hline
\end{tabular}




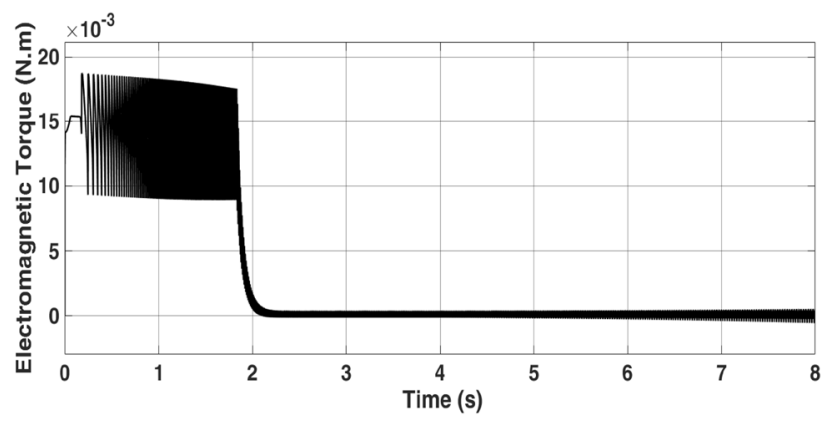

Fig. 15 Electromagnetic torque waveform in faulty operation mode case 3

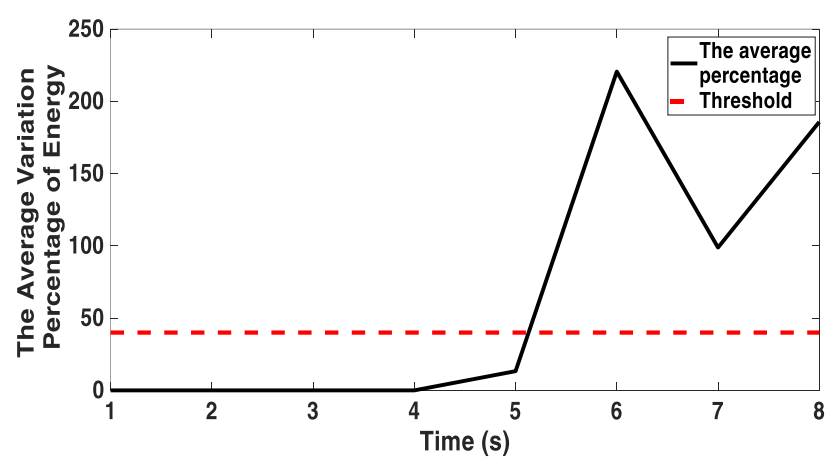

Fig. 16 The average variation percentage of faulty and healthy mode energy in case 3

Table 6 The energies of the healthy and faulty mode of case 3 and the calculated average variations

\begin{tabular}{lrlll}
\hline Energy operation mode & \multicolumn{1}{c}{$\mathrm{E}_{10}$} & $\mathrm{E}_{11}$ & $\mathrm{E}_{12}$ & $\mathrm{E}_{13}$ \\
\hline Healthy & 3.8568 & 12.0852 & 45.2893 & 420.0062 \\
Fault case 3 & 4.6204 & 15.7651 & 83.5905 & 945.5180 \\
Variation percentage & $19.80 \%$ & $30.45 \%$ & $84.57 \%$ & $125.12 \%$ \\
$\begin{array}{l}\text { Average variation percent- } \\
\text { age }\end{array}$ & $64.98 \%$ & & & \\
\hline
\end{tabular}

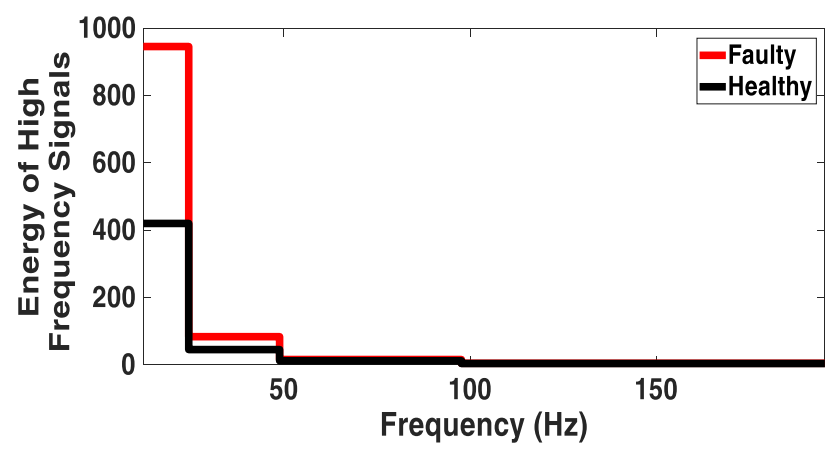

Fig. 17 Frequency-energy diagram for fault case 3

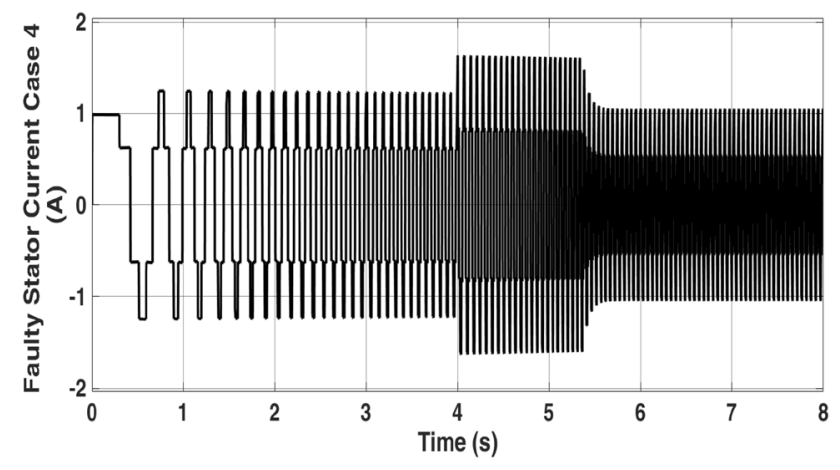

Fig. 18 Stator current waveform in faulty operation mode case 4

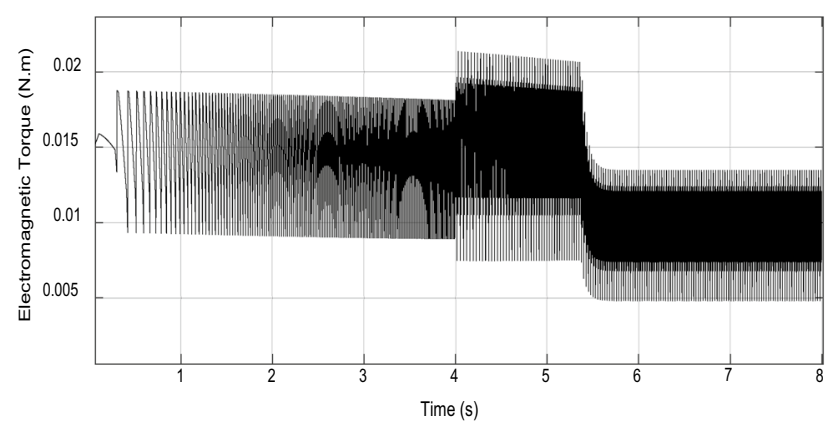

Fig. 19 Electromagnetic torque waveform in faulty operation mode case 4

is constantly $40 \%$. The rising average variation percentage of energy must reach higher than the fault detection threshold to be diagnosed. According to this Figure, one can say that the time that it takes for our fault detection algorithm to declare the fault occurrence is about $1.14 \mathrm{~s}$ after the initial time that it emerges. It is clear that this time is directly related to the assigned threshold.

Now, as the approach for the last 2 cases, Table 6 is rendered to illustrate the energies of the healthy and faulty modes, also the frequency-energy diagram is shown in Fig. 17.

The average variation percentage of faulty and healthy mode energy here is $64.98 \%$ which is more than $40 \%$. Therefore, it confirms the truthfulness of the algorithm since it passes the threshold amount by far.

\subsection{Case 4}

In this section, a load torque of $0.01 \mathrm{~N}$ m is included in the model to have a better view of the algorithm in the loading condition as well and the results will be shown. The characteristics of the fault considered in the loading condition are the same as case 1. Moreover, the new healthy high-frequency signals' energies were required for this special case too, considering the load torque. 


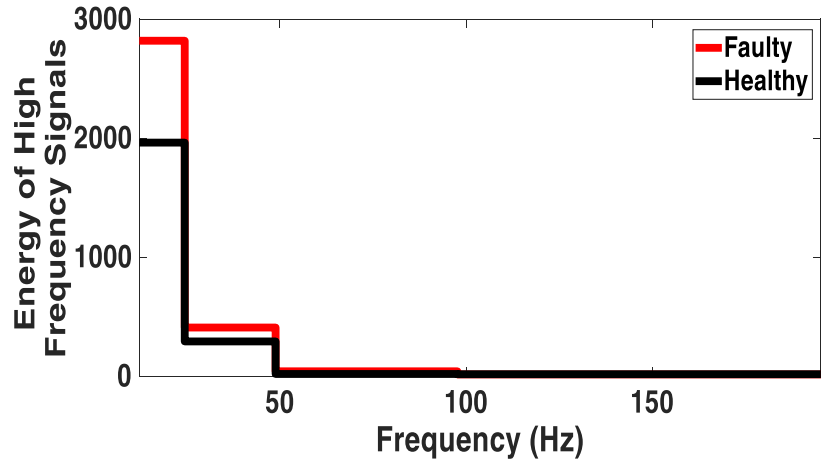

Fig. 20 Frequency-energy diagram for fault case 4

Figures 18, 19, and 20 illustrate the faulty stator current, the electromagnetic torque, and the frequency-energy diagrams respectively. Table 7 is proposed to give a view of the energy's numerical data.

The average variation percentage of faulty and healthy mode energy, in this case, is $49.12 \%$ which is more than $40 \%$. Thus, it accredits the algorithm since it passes the threshold amount.

\subsection{Case 5}

This case takes the two faulty stator phases into consideration. Also, no load torque is considered in the model here. To this end, faults are applied to two phases of stator instead of one, in comparison with the previous scenarios, and the respective results of the algorithm are proposed. To make it clear, fault case 2 occurs in the phase " $a$ " while fault case 1 happens in the phase " $b$ " of stator. Below, the stator currents' signals of two faulty phases " $a$ " and " $b$ " are shown in Figs. 21 and 22. As these diagrams show, two phases of stator have undergone the faulty situation and hence, their currents' amplitudes have increased; this has happened from $t=0$ in phase "a" and from $t=4$ in phase " $b$ " due to their different fault characteristics. The fault has influenced the electromagnetic too which is illustrated in Fig. 23. Also, the numerical information is given in Table 8 while Fig. 24 includes the frequency-energy diagram. This Figure helps with a better understanding of the difference between faulty and healthy situation considering the fault detection criteria.

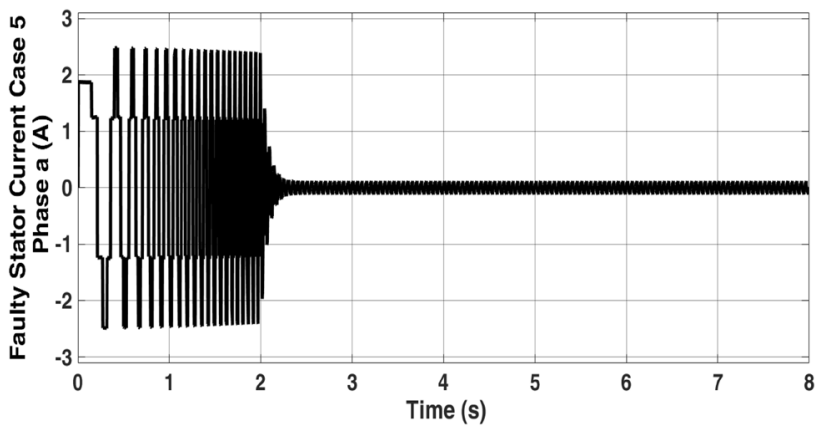

Fig. 21 Stator current phase "a" waveform in faulty operation mode case 5

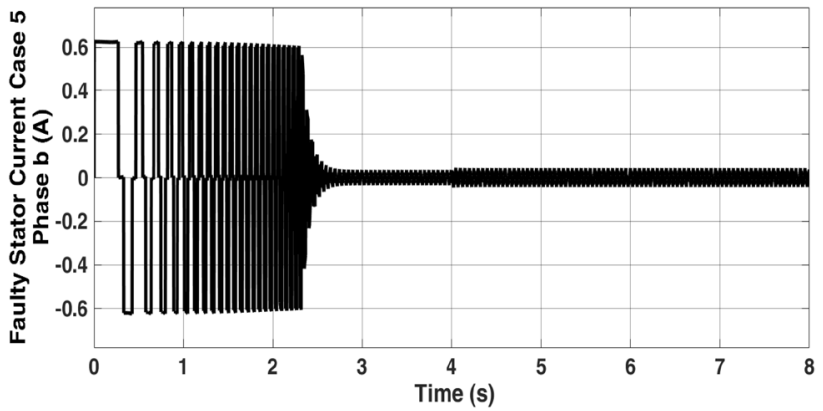

Fig. 22 Stator current phase "b" waveform in faulty operation mode case 5

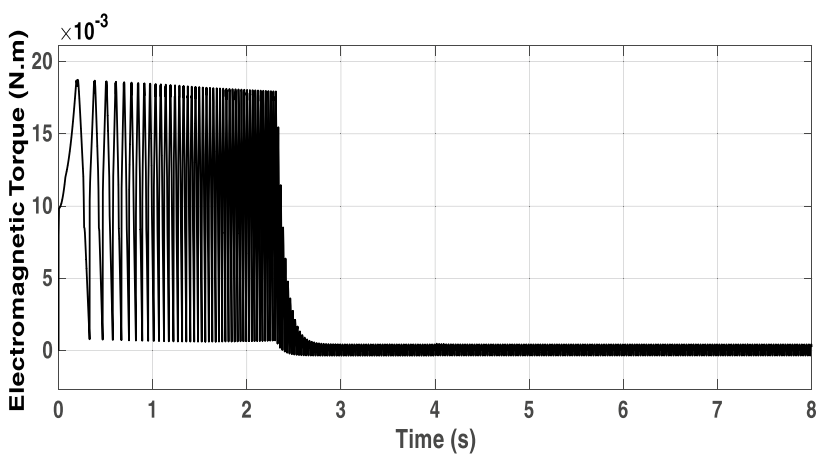

Fig. 23 Electromagnetic torque waveform in faulty operation mode case 5
Table 7 The energies of the healthy and faulty mode of case 4 and the calculated average variations

\begin{tabular}{lcccr}
\hline Energy operation mode & $\mathrm{E}_{10}$ & $\mathrm{E}_{11}$ & $\mathrm{E}_{12}$ & \multicolumn{1}{c}{$\mathrm{E}_{13}$} \\
\hline Healthy & 16.2272 & 18.1233 & 291.6011 & 1962.0319 \\
Fault case 4 & 14.3298 & 40.6854 & 408.4370 & 2817.9173 \\
Variation percentage & $-11.70 \%$ & $124.50 \%$ & $40.07 \%$ & $43.62 \%$ \\
Average variation percentage & $49.12 \%$ & & & \\
\hline
\end{tabular}


Table 8 The energies of the healthy and faulty mode of case 5 and the calculated average variations

\begin{tabular}{lrrrr}
\hline Energy operation mode & \multicolumn{1}{c}{$\mathrm{E}_{10}$} & \multicolumn{1}{c}{$\mathrm{E}_{11}$} & \multicolumn{1}{c}{$\mathrm{E}_{12}$} & \multicolumn{1}{c}{$\mathrm{E}_{13}$} \\
\hline Healthy & 3.8568 & 12.0852 & 45.2893 & 420.0062 \\
Fault case 5 & 9.3736 & 34.4155 & 122.5745 & 1470.5938 \\
Variation percentage & $143.04 \%$ & $184.77 \%$ & $170.65 \%$ & $250.14 \%$ \\
Average variation percentage & $187.15 \%$ & & & \\
\hline
\end{tabular}

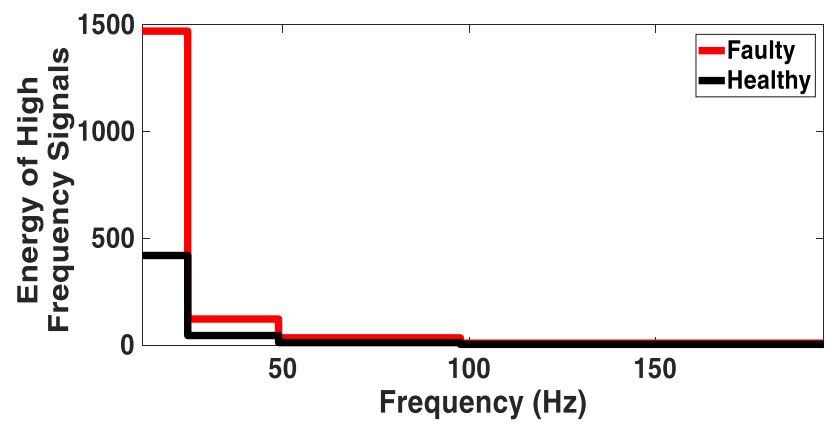

Fig. 24 Frequency-energy diagram for fault case 5

The average variation percentage of faulty and healthy mode energy, in this case, is $187.15 \%$ which is more than $40 \%$. Thus, it accredits the algorithm since it passes the threshold amount greatly.

\section{Conclusion}

A fault detection method for the stator inter-turn fault of the BLDC motor, which has been modeled through Matlab and ADAMS software to be more real and close to the reality of the BLDC motor, is perused in this paper. The algorithm was a signal-based method called discrete wavelet transform which is roughly a modern method that has proved itself in different fields of science. DWT was applied to five fault cases, two of which were abrupt constant faults and differed with each other in time and severity of fault occurrence. In one of the cases, the severity of fault was increased by two-fold; also, the initial time of fault occurrence was the beginning of the simulation in one of the cases while it was not in the other. Case three described a time variable fault that started through the stable phase of stator current and grew with time. In this case, the time it takes to detect the fault was calculated whereas in the two previous cases the fault occurrence was sudden and so was the detection of it. Case four was about checking the algorithm in the presence of load torque in the motor model while case five described a faulty situation in two phases of stator rather than one. After running the simulation for each case, applying DWT, extracting energy amounts, calculating the average variation percentage of faulty mode to healthy mode and finally comparing it with a pre-assigned threshold, one could observe that the aforesaid fault detection criteria would be higher than the threshold in case of fault occurrence. Hence, the validation of the method was shown. Although this algorithm has shown successful outcomes in fault detection, it is not capable of finding the source of defect. Plus, the threshold amount is better to be calculated online and adaptively. In addition, to give a proper result, this method requires that the signal's noise does not be extremely high.

For further studies, the experimental validation of the total method would be a great subject of research. Also, in future work, this algorithm could be implemented in reality on a micro-controller such as MCU, DSP, FPGA.

\section{Compliance with ethical standards}

Conflict of interest The authors declare that they have no conflict of interest.

\section{References}

1. Salehifar M, Moreno-Eguilaz M, Putrus G, Barras P (2016) Simplified fault tolerant finite control set model predictive control of a five-phase inverter supplying BLDC motor in electric vehicle drive. Electr Power Syst Res 132:56-66

2. Rkhissi-Kammoun Y, Ghommam J, Boukhnifer M, Mnif F (2019) Two current sensor fault detection and isolation schemes for induction motor drives using algebraic estimation approach. Math Comput Simul 157:39-62

3. Mini VP, Sivakotaiah S, Ushakumari S (2010) Fault detection and diagnosis of an induction motor using fuzzy logic. In: Proceedings of the 2010 IEEE region 8 international conference on computational technologies in electrical and electronics engineering (SIBIRCON). no 3, pp 459-464

4. Salehifar M, Moreno-Equilaz M (2016) Fault diagnosis and fault-tolerant finite control set-model predictive control of a multiphase voltage-source inverter supplying BLDC motor. ISA Trans 60:143-155

5. Lin CL, Shieh NC, Tung PC (2002) Robust wavelet neuro control for linear brushless motors. IEEE Trans Aerosp Electron Syst 38(3):918-932

6. Zhang M, Xia C, Tian Y, Liu D, Li Z (2008) Speed control of brushless DC motor based on single neuron PID and wavelet 
neural network. In: 2007 IEEE international conference on control and automation. vol 00, no 3, pp 617-620

7. Aghili F (2011) Fault-tolerant torque control of BLDC motors. IEEE Trans Power Electron 26(2):355-363

8. Patton RJ, Uppal FJ, Simani S, Polle B (2010) Robust FDI applied to thruster faults of a satellite system. Control Eng Pract 18(9):1093-1109

9. Xiao B, Yin S (2016) Velocity-free fault-tolerant and uncertainty attenuation control for a class of nonlinear systems. IEEE Trans Ind Electron 63(7):4400-4411

10. Henry D (2008) Fault diagnosis of microscope satellite thrusters using H-infinity/H_filters. J Guid Control Dyn 31(3):699-711

11. Valdes A, Khorasani K (2010) A pulsed plasma thruster fault detection and isolation strategy for formation flying of satellites. Appl Soft Comput J 10(3):746-758

12. Park JK, Hur J (2016) Detection of inter-turn and dynamic eccentricity faults using stator current frequency pattern in IPM-type BLDC motors. IEEE Trans Ind Electron 63(3):1771-1780

13. Du B, Wu S, Han S, Cui S (2016) Interturn fault diagnosis strategy for interior permanent-magnet synchronous motor of electric vehicles based on digital signal processor. IEEE Trans Ind Electron 63(3):1694-1706

14. Zanardelli WG, Strangas EG, Khalil HK, Miller JM (2005) Wavelet-based methods for the prognosis of mechanical and electrical failures in electric motors. Mech Syst Signal Process 19(2):411-426

15. Zandi O, Poshtan J (2018) Brushless DC motor bearing fault detection using hall effect sensors and a two-stage wavelet transform. In: 26th Iranian conference electrical engineering ICEE 2018. pp 827-833

16. Zandi O, Poshtan J (2019) Fault diagnosis of brushless DC motors using built-in hall sensors. IEEE Sens J 19(18):8183-8190

17. Benchabane F, Guettaf A, Yahia K, Sahraoui M (2018) Experimental investigation on induction motors inter-turns short-circuit and broken rotor bars faults diagnosis through the discrete wavelet transform. Elektrotechnik und Informationstechnik 135(2):187-194

18. Prins S, Mini VP, Mayadevi N, Harikumar R (2018) Detection of broken rotor bars using multilevel wavelet decomposition. In: Proceedings of the 2nd international conference on trends in electronics and informatics, ICOEI 2018. no ICOEI, pp 621-626

19. Rajagopalan S, Restrepo JA, Aller JM, Habetler TG, Harley RG (2005) Wigner-Ville distributions for detection of rotor faults in brushless DC (BLDC) motors operating under non-stationary conditions. In: SDEMPED 2005-international symposium on diagnostics for electric machines, power electronics and drives. no September, pp 7-9

20. Rajagopalan S, Aller JM, Restrepo JA, Habetler TG, Harley RG (2007) Analytic-wavelet-ridge-based detection of dynamic eccentricity in brushless direct current (BLDC) motors functioning under dynamic operating conditions. IEEE Trans Ind Electron 54(3):1410-1419

21. Tashakori A, Ektesabi M (2013) Fault diagnosis of in-wheel BLDC motor drive for electric vehicle application. In: IEEE intelligent vehicles symposium (IV). pp 925-930

22. Park BG, Lee KJ, Kim RY, Kim TS, Ryu JS, Hyun DS (2011) Simple fault diagnosis based on operating characteristic of brushless direct-current motor drives. IEEE Trans Ind Electron 58(5):1586-1593

23. Abed WR, Sutton R, Sharma SK (2013) Fault diagnosis of brushless DC motor for an aircraft actuator using a neural wavelet network. no 2, pp 05-05

24. Awadallah MA, Morcos MM, Gopalakrishnan S, NehI TW (2006) Detection of stator short circuits in VSI-Fed brushless DC motors using wavelet transform. IEEE Trans Energy Convers 21(1):1-8

25. Dash RN, Subudhi B, Das S (2010) Induction motor stator interturn fault detection using wavelet transform technique. In: 2010 5th international conference on industrial and information systems ICIIS 2010. pp 436-441

26. Ramesh Balaji SM, Muniraj C, Mekala N (2015) Wavelet transform based fault diagnosis of BLDC motor drive. TELKOMNIKA Indones J Electr Eng 14(3):434-440

27. Li X-X, Zhang Q-J, Xiao H-J (2005) The design of brushless DC motor servo system based on wavelet ANN. no August, pp 929-933

28. Zhou JH, Zhong ZW, Luo M, Shao C (2009) Wavelet-based correlation modeling for health assessment of fluid dynamic bearings in brushless DC motors. Int J Adv Manuf Technol 41(5-6):421-429

29. Santosh G, Kumar MR (2015) Speed control of DTC based brushless DC motor using PI, PID, SMC controllers. SSRG Int J Electr Electron Eng 2(6):13-19

30. Baldursson S (2005) BLDC motor modelling and control-a Matlab ${ }^{\circ} /$ Simulink implementation. Master thesis work. pp 8-13

31. Jeon YS, Mok HS, Choe GH, Kim DK, Ryu JS (2002) A new simulation model of BLDC motor with real back EMF waveform. pp 217-220

32. Cheema MAM, Fletcher JE, Xiao D, Rahman MF (2016) A linear quadratic regulator-based optimal direct thrust force control of linear permanent-magnet synchronous motor. IEEE Trans Ind Electron 63(5):2722-2733

33. Hanselman D (2006) Brushless permanent magnet motor design, 2nd edn, vol 2. Magna Physics Publishing, Lebanon, $\mathrm{OH}$

34. Kim KT, Lee ST, Hur J (2014) Diagnosis technique using a detection coil in BLDC motors with inter-turn faults. IEEE Trans Magn 50(2):2-5

35. Riba Ruiz JR, Rosero JA, Garcia Espinosa A, Romeral L (2009) Detection of demagnetization faults in permanent-magnet synchronous motors under nonstationary conditions. IEEE Trans Magn 45(7):2961-2969

36. Cabal-Yepez E, Garcia-Ramirez AG, Romero-Troncoso RJ, GarciaPerez A, Osornio-Rios RA (2013) Reconfigurable monitoring system for time-frequency analysis on industrial equipment through STFT and DWT. IEEE Trans Ind Inform 9(2):760-771

37. Zhang J, Hang J, Cheng M (2016) Diagnosis of mechanical unbalance fault in permanent magnet synchronous machine drives. Electr Power Compon Syst 44(12):1408-1417

Publisher's Note Springer Nature remains neutral with regard to jurisdictional claims in published maps and institutional affiliations. 